REVIEW

\title{
Life in the littoral zone: lactobacilli losing the plot
}

\author{
P Hay
}

Sex Transm Infect 2005;81:100-102. doi: 10.1136/sti.2003.007161

Recurrent bacterial vaginosis is a challenge for those affected by it, and their physicians. Our inability to prevent relapse after treatment, may be because of the flawed approach of using antibiotics to treat a condition that is an imbalance rather than an infection. The maintenance of a healthy lactobacillus population offers an approach to preventing relapse: the problem is how best to do this. Physiological approaches such as the use of hydrogen peroxide, lactic acid, and exogenous lactobacilli need to be explored further. The role of bacterial vaginosis as a risk factor for acquisition of HIV and other STIs is a further impetus to attempting to prevent bacterial vaginosis from recurring.

Correspondence to: Dr Phillip Hay, Courtyard Clinic, St George's Hospital, Blackshaw Road, London SW17 0QT, UK; phay@sghms.ac.uk

Accepted for publication 5 August 2004
$\mathrm{T}$ he aetiology of bacterial vaginosis (BV) continues to be debated more than 20 years after the name was adopted, and nearly 50 years after Gardner and Dukes first described clue cells. ${ }^{1}$ Some behavioural studies have associated risk taking sexual behaviour with BV. For instance, a Swedish study identified risk factors for BV as being similar to those for chlamydia. $^{2}$ A recent Australian study associated BV with having three or more male partners in the preceding year, at least one female sexual partner in the past 12 months, as well as a past pregnancy and smoking. ${ }^{3}$

The most compelling evidence against BV being exclusively a sexually transmitted infection (STI) is its prevalence in virgin women. Bump and Buesching found clue cells in 15\% of 68 sexually active adolescents and $12 \%$ of 52 virgin adolescents in a survey conducted in a high school. ${ }^{4}$ More recently, a study of female army recruits in the United States detected BV in $28 \%$ of sexually experienced women and $18 \%$ of nonsexually experienced women. ${ }^{5}$

The reported point prevalence of BV varies widely between different populations, with more than 50\% women in rural Uganda having BV in the Rakai study. ${ }^{6}$ Lifetime incidence has not been studied. Given the high frequency with which asymptomatic BV and intermediate flora developed in studies of volunteers ${ }^{78}$ it seems likely that most women will develop $\mathrm{BV}$ at some point. The point prevalence therefore reflects the balance of occurrence, persistence and spontaneous clearance in a population. It is important that we learn how to prevent relapse/incidence of $\mathrm{BV}$ to help the symptomatic women who experience considerable distress from recurrent $\mathrm{BV}$, as well as aiming for a potential public health impact to reduce $\mathrm{BV}$ associated adverse pregnancy outcomes and HIV transmission.

Rather than viewing BV as an overgrowth of anaerobic bacteria, some authors have described it as a deficiency of lactobacilli. We know little about what influences the lactobacillus flora that establishes itself as the predominant vaginal organism at menarche in "healthy women." At this time, under the influence of increasing levels of oestrogen the vaginal epithelium becomes stratified and the $\mathrm{pH}$ of vaginal fluid falls. The vaginal flora becomes dominated by lactobacilli; often more than one subspecies is present. Lactobacillus crispatus and $L$ gensenii have been identified as common high hydrogen peroxide producing vaginal strains. ${ }^{9}$ The subspecies that thrive in the vagina are different from those in the gut, and we know little about their origin, and the mechanisms that support their persistence in the vagina. In the gut, production of IgA specific to commensal species helps to prevent an inflammatory response when the organisms come into contact with the mucosal surface. Is there a similar tolerance in the vagina? And how is such tolerance established? If this is organism specific, using exogenous hydrogen peroxide producing lactobacilli to recolonise the vagina of women with recurrent BV may not be a successful strategy. A recent study of adolescent women reported a predominance of transforming growth factor beta (TGF- $\beta$ ) and interleukin (IL) 10 production by peripheral blood mononuclear cells in response to $L$ crispatus antigens. ${ }^{10}$ The authors comment that TGF- $\beta$, together with IL-10, counteracts the effects of proinflammatory cytokines, thereby creating a condition of tolerance. They did not know how species specific such a response is. The lactobacilli maintain their dominance through a combination of acidity, hydrogen peroxide, lactocins, and other bacteriocins to inhibit the growth of other bacteria. One key factor is that the organisms associated with BV can overcome such inhibition at a $\mathrm{pH}$ $>4.5^{11}$ and have a mutually symbiotic relationship. $^{12}{ }^{13}$ These mechanisms were reviewed recently by Janet Wilson in this journal. ${ }^{14}$ Additional mechanisms might include the production of biosurfactants and collagen binding proteins that inhibit pathogen adhesion and to some extent displace pathogens, as has been shown in the gut. ${ }^{15}$

The vagina, however, is not a steady state ecosystem. As the menstrual cycle becomes established there are marked cyclical changes

Abbreviations: BV, bacterial vaginosis; IL, interleukin; TGF- $\beta$, transforming growth factor beta; STI, sexually transmitted infections; WSW, women who have sex with women 
in the environment, which can be compared to life in the littoral zone of the seashore. Levels of oestrogen and progesterone alter, changing the endogenous environment for lactobacilli by influencing cell surface receptor expression, ${ }^{16}$ levels of glycogen and glucose as substrate, and levels of vaginal $\mathrm{pH}$. Additionally, factors exogenous to the vagina, such as quantity of cervical mucus and menstrual products with a pH of 7-8, all ebb and flow. The influence of hormones over the course of the menstrual cycle have been studied little in the aetiology of BV. ${ }^{17} 18$ In a mouse model of chlamydia infection progesterone is required to make the animal susceptible to chlamydia. ${ }^{19} 20$ This is associated with a dramatic change in the vaginal flora, with an overgrowth of many organisms that appears similar to BV. This is an area requiring further study. Oestrogen may be protective in women as the prevalence of BV has been lower in women using combined oral contraception ${ }^{5}$ and tends to decrease during pregnancy. ${ }^{21}$

In addition to inescapable physiological changes that occur over the course of a menstrual cycle, there are multiple behavioural factors that can challenge the ecological niche of the lactobacilli. Washing practices will have a variable effect on the flora. Douching is generally associated with BV, but prospective studies investigating the potential benefit of stopping douching have not been done. An American study of 250 adolescent women confirmed associations between BV and multiple partners, recent sexual intercourse and gonorrhoea. ${ }^{22}$ However, douching after menses was the factor most strongly associated with BV. The authors comment that we still do not know if the douching is causal, or a response to symptoms of BV. As a young woman becomes sexually active additional environmental stresses may come into play. Semen has a $\mathrm{pH}>7.0$. It has been estimated that a normal level of lactobacilli will take several hours to reacidify the vagina following one episode of unprotected intercourse. ${ }^{23}$ If condoms are used the spermicide may disrupt vaginal epithelium more than unprotected intercourse does. If they are not used there is the risk of acquiring STIs and the secondary effects that they have on the vaginal milieu. Gardner and Dukes were able to induce BV in women by inoculating them with fresh vaginal discharge from another woman with BV, while vaginal flora cultured in vitro for even 12 hours was less likely to induce BV. ${ }^{24}$ Inoculation of organisms from a male or female partner may therefore be one means of initiating BV. Women who have sex with women (WSW) have been found to have a high prevalence of $\mathrm{BV}$ in several studies. ${ }^{25-27}$ A high concordance rate among couples to have either BV or normal flora has been found, with $95 \%$ concordance in one study. ${ }^{26}$ Further support for the hypothesis of a sexually transmissible agent between women was provided by the association between $\mathrm{BV}$ and a higher lifetime number of female sex partners, failure to always clean an insertive sex toy before use, and oral-anal sex with female partners.

Bacteria from the gut, such as Escherichia coli and group B streptococci commonly colonise the vagina. Little is known about how much this affects the bacterial balance of the vagina. Is there an influence of gut lactobacilli? Lactobacilli ingested from yoghurt might harbour phages, potentially toxic to vaginal lactobacilli in up to $25 \%$ of cases. ${ }^{28}{ }^{29}$ This hypothesis has been expanded to include the potential role of smoking in inducing a lytic phase of phage infection to explain the association between $\mathrm{BV}$ and smoking. ${ }^{29} \mathrm{BV}$ is associated with STIs including gonorrhoea, chlamydia, and HIV. There are some in vitro data supporting the hypothesis that BV increases susceptibility to STIs through mechanisms such as cleavage of $\operatorname{IgA}$ and mucins ${ }^{30}$ and lack of hydrogen peroxide. ${ }^{11}$ In a clinical study of female partners of men with urethral infections, BV was strongly predictive of both gonorrhoea (odds ratio (OR), 4.1; 95\% confidence interval (CI) 1.7 to 9.7 ) and chlamydia (OR, $3.4 ; 95 \% \mathrm{CI}, 1.5$ to 7.8$){ }^{31}$ This association does not exclude the possibility that the BV is arising as a consequence of the STI, rather than inducing susceptibility to STI acquisition. It is likely that the STIs alter vaginal physiology by inducing inflammation, increasing production of pus, mucus, and sometimes blood from the cervix. This is likely to alter vaginal $\mathrm{pH}$ and make the environment less conducive to survival of lactobacilli and promote the development of BV.

Our increasing understanding of the factors controlling the microbial interactions in the vaginal environment has not yet led to successful interventions to prevent relapse of BV. The use of exogenous lactobacilli as a probiotic has not so far proved successful. However, understanding the influence of cyclical changes should enable us to focus on supporting endogenous lactobacilli when they are most vulnerable. The use of repeated courses of antibiotics is not an attractive long term proposition as inevitably bacterial resistance will develop, and the antibiotics may induce unwanted side effects for those treated. A more physiological approach would be to use acidification and/or hydrogen peroxide to assist the lactobacilli during menstruation or after unprotected sexual intercourse. There are uncontrolled studies showing that hydrogen peroxide is successful. ${ }^{32}{ }^{33}$ Such an approach warrants further study in randomised controlled trials. Given the dramatic environmental changes that occur over the course of a menstrual cycle, with additional exogenous factors, it would be surprising if lactobacilli were able to survive every environmental insult that comes their way in such a littoral zone, and don't occasionally lose their plot in the ecosystem.

Conflict of interest statement: The author has received payment for lectures and consultancy from Osmetech, which is developing a diagnostic test for bacterial vaginosis; $3 \mathrm{M}$, which manufacturers $0.75 \%$ metronidazole vaginal gel; and Pharmacia and Upjohn, which manufacture $2 \%$ clindamycin vaginal cream and clindamycin capsules. He has conducted clinical trials for which his unit has received reimbursement from Osmetech; 3M; Pharmacia and Upjohn, and he has received financial support to attend conferences from these companies.

\section{REFERENCES}

1 Gardner HL, Dukes CD. Haemophilus vaginalis vaginitis. A newly defined specific infection previously classified "nonspecific" vaginitis. Am J Obstet Gynecol 1955;69:962-76.

2 Nilsson U, Hellberg D, Shoubnikova $M$, et al. Sexual behavior risk factors associated with bacterial vaginosis and Chlamydia trachomatis infection. Sex Transm Dis 1997;24:241-6.

3 Smart S, Singal A, Mindel A. Social and sexual risk factors for bacterial vaginosis. Sex Transm Infect 2004;80:58-62.

4 Bump RC, Buesching WJ. Bacterial vaginosis in virginal and sexually active adolescent females: evidence against exclusive sexual transmission. Am J Obstet Gynecol 1988;158:935-9.

5 Yen S, Shafer MA, Moncada J, et al. Bacterial vaginosis in sexually experienced and non-sexually experienced young women entering the military. Obstet Gynecol 2003;102(5 Pt 1):927-33.

6 Paxton LA, Sewankambo N, Gray R, et al. Asymptomatic non-ulcerative genital tract infections in a rural Ugandan population. Sex Transm Infect 1998;74:421-5.

7 Priestley CJ, Jones BM, Dhar J, et al. What is normal vaginal flora? Genitourin Med 1997; 73:23-8.

8 Keane FE, Ison CA, Taylor-Robinson D. A longitudinal study of the vaginal flora over a menstrual cycle. Int J STD AIDS 1997;8:489-94.

9 Antonio MA, Hawes SE, Hillier SL. The identification of vaginal Lactobacillus species and the demographic and microbiologic characteristics of women colonized by these species. J Infect Dis 1999;180:1950-6.

10 Alvarez-Olmos MI, Barousse MM, Rajan L, et al. Vaginal lactobacilli in adolescents: presence and relationship to local and systemic immunity, and to bacterial vaginosis. Sex Transm Dis 2004;31:393-400.

11 Klebanoff SJ, Hillier SL, Eschenbach DA, et al. Control of the microbial flora of the vagina by H2O2-generating lactobacilli. J Infect Dis $1991 ; 164: 94-100$

12 Pybus V, Onderdonk $A B$. Evidence for a commensal, symbiotic relationship between Gardnerella vaginalis and Prevotella bivia involving ammonia: potential significance for bacterial vaginosis. $J$ Infect Dis 1997; 175:406-13. 
13 Pybus V, Onderdonk AB. A commensal symbiosis between Prevotella bivia and Peptostreptococcus anaerobius involves amino acids: potential significance to the pathogenesis of bacterial vaginosis. FEMS Immunol Med Microbiol 1998;22:317-27.

14 Wilson J. Managing recurrent bacterial vaginosis. Sex Transm Infect 2004:80:8-11.

15 Heinemann C, van Hylckama Vlieg JE, Jannsen DB, et al. Purification and characterization of a surface-binding protein from Lactobacillus fermentum RC-14 that inhibits adhesion of Enterococcus faecalis 1131. FEMS Microbiol Lett 2000;190:177-80.

16 Chan RC, Bruce AW, Reid G. Adherence of cervical, vaginal and distal urethral normal microbial flora to human uroepithelial cells and the inhibition of adherence of gram-negative uropathogens by competitive exclusion. J Urol 1984;131:596-601.

17 Eschenbach DA, Hillier S, Critchlow C, et al. Diagnosis and clinical manifestations of bacterial vaginosis. Am J Obstet Gynecol 1988; 158:819-28

18 Taylor-Robinson D, Hay P. The pathogenesis of the clinical signs of BV and possible reasons for its occurrence. Int J STD AIDS 1997;8S:13-6.

19 Furr PM, Taylor-Robinson D. The influence of hormones on the bacterial flora of the mouse vagina and implications for human disease. Microb Ecol Hlth Dis $1991 ; 4: 141-8$

20 Tuffrey M, Taylor-Robinson D. Progesterone as a key factor in the development of a mouse model for genital tract infection with Chlamydia trachomatis. FEMS Microbiology Lett 1981;12:111-5.

21 Hay PE, Morgan DJ, Ison CA, et al. A longitudinal study of bacterial vaginosis during pregnancy. Br J Obstet Gynaecol 1994;101:1048-53.

22 Schwebke JR, Desmond RA, Oh MK. Predictors of bacterial vaginosis in adolescent women who douche. Sex Transm Dis 2004;31:433-6.
23 Boskey ER, Telsch KM, Whaley KJ, et al. Acid production by vaginal flora in vitro is consistent with the rate and extent of vaginal acidification. Infect Immun 1999;67:5170-5

24 Criswell BS, Ladwig CL, Gardner HL, et al. Haemophilus vaginalis: vaginitis by inoculation from culture. Obstet Gynecol 1969:33:195-9.

25 Bailey JV Farquhar C, Owen C, et al. Sexually transmitted infections in women who have sex with women. Sex Transm Infect 2004;80:244-6.

26 Marrazzo JM, Koutsky LA, Eschenbach DA, et al. Characterization of vaginal flora and bacterial vaginosis in women who have sex with women. J Infect Dis 2002; 185:1307-13.

27 Fethers K, Marks C, Mindel A, et al. Sexually transmitted infections and risk behaviours in women who have sex with women. Sex Transm Infect 2000;76:345-9.

28 Kilic AO, Pavlova SI, Ma WG, et al. Analysis of Lactobacillus phages and bacteriocins in American dairy products and characterization of a phage isolated from yogurt. Appl Environ Microbiol 1996;62:2111-6.

29 Blackwell AL. Vaginal bacterial phaginosis? Sex Transm Infect 1999;75:352-3.

30 Cauci S Monte R, Driussi S, et al. Impairment of the mucosal immune system: $\lg A$ and $\lg M$ cleavage detected in vaginal washings of a subgroup of patients with bacterial vaginosis. J Infect Dis 1998; 178:1698-706.

31 Wiesenfeld HC, Hillier SL, Krohn MA, et al. Bacterial vaginosis is a strong predictor of Neisseria gonorrhoeae and Chlamydia trachomatis infection. Clin Infect Dis 2003;36:663-8.

32 Cardone A, Zarcone R, Borrelli A, et al. Utilisation of hydrogen peroxide in the treatment of recurrent bacterial vaginosis. Minerva Ginecol 2003;55:483-92

33 Winceslaus SJ, Calver G. Recurrent bacterial vaginosis - an old approach to a new problem. Int J STD AIDS 1996;7:284-7.

\section{Register now!}

10th European Forum on Quality Improvement in Health Care 13-15 April 2005, ExCel Conference Centre, London For further information on how to register please go to: http://www.quality.bmipg.com 